\title{
Comparison of clinical and radiological outcomes in intertrochanteric fractures treated with InterTAN nail against conventional cephalomedullary nails: a systematic review
}

\author{
Akshay Date ${ }^{\ddagger * *, 1}$ (D), Mrinalini Panthula $a^{\ddagger 2}$ \& Anita Bolina ${ }^{2}$ \\ ${ }^{1}$ Basildon and Thurrock University Hospital, Nethermayne, Basildon, Essex, SS16 5NL, UK \\ ${ }^{2}$ Imperial College London, Exhibition Road, South Kensington, London SW7 2BU, UK \\ *Author for correspondence: Tel.: +44 779249 7242; akshaydate92@hotmail.com \\ ${ }^{\ddagger}$ Authors contributed equally.
}

Intertrochanteric fractures, accountable for $50 \%$ of hip fractures, can be fixed with cephalomedullary devices such as Proximal Femoral Nail Antirotation (PFNA ${ }^{T M}$ ), Gamma3 nailing system and TRIGEN ${ }^{T M}$ InterTAN ${ }^{T M}$ nail (IT). IT uniquely uses two cephalocervical screws that allow for linear compression and provide additional resistance to femoral head rotation. A literature review assessing clinical outcomes of these devices was conducted, with 14 studies enrolling 3104 patients meeting the inclusion criteria. PFNA and Gamma3 had better intraoperative outcomes compared with IT; however, IT had superior implant-related outcomes of cut-out and screw migration. No difference was found between IT and PFNA or Gamma3 in Harris Hip Scores, time to union, malunion and nonunion. Further long-term studies are needed to evaluate clinical outcomes and cost-effectiveness of cephalomedullary devices.

Lay abstract: Hip fractures remain a significant cause of morbidity and mortality within healthcare systems, with an estimated global incidence of 1.6 million fractures annually. Certain intertrochanteric fractures - a specific subtype of hip fractures - are treated surgically using intramedullary nailing devices such as Proximal Femoral Nail Antirotation $\left(\right.$ PFNA $\left.^{T M}\right)$, Gamma3 nailing system and InterTAN ${ }^{T M}$ nail (IT). IT is unique, in that it uses two proximal screws. This study assessed the clinical and radiological outcomes of using IT over the traditional one-screw devices PFNA and Gamma3.

First draft submitted: 25 October 2020; Accepted for publication: 18 November 2020; Published online: 7 December 2020

Hip fractures are common orthopedic injuries, with an estimated annual incidence of over 1.6 million fractures globally [1,2]. In the UK, the healthcare and social costs of hip fractures total over GBP£2 billion annually [2]. Hip fractures are associated with significant morbidity and carry a high 30-day postoperative mortality rate of $6.1 \%$ [3]. It is therefore important to consider operative and postoperative implications of surgical techniques used for fracture fixation.

Intertrochanteric fractures account for up to half of hip fractures and are usually seen in the elderly demographic, resulting from low-energy injuries [4]. Surgical procedures in intertrochanteric fractures are primarily influenced by fracture pattern. Guidelines recommend the use of sliding hip screws to treat stable fractures, whereas subtrochanteric or unstable fractures are managed with an intramedullary device [4,5]. Intramedullary devices include the Proximal Femoral Nail Antirotation (PFNA ${ }^{\mathrm{TM}}$, IN, USA) nail, Gamma3 (MI, USA) nailing system and TRIGEN $^{\top M}$ InterTAN $^{\top M}$ (London, UK) nail (IT).

IT differs from traditional intramedullary devices, in that it uniquely uses two cephalocervical screws that allow for linear compression and provide additional resistance to femoral head rotation. Biomechanical studies in cadaveric models have found IT to provide greater biomechanical stability compared with single-screw devices [6-8]. IT has also been shown in cadavers to have significantly greater biomechanical strength, with reduced varus collapse and 
femoral head rotation, compared with the PFNA and Gamma3 nails $[7,8]$. Recent literature with regard to clinical studies also suggests the newer generation IT may offer additional rotational stability while reducing postoperative pain, implant failure and nonunion [9]. This systematic review aims to evaluate whether InterTAN offers better clinical or radiological outcomes compared with conventional PFNA and Gamma3 nails for the surgical treatment of intertrochanteric fractures.

\section{Methods}

\section{Literature search}

A systematic review of the literature was performed using the following databases: PubMed, Medline (1946-present) and Embase (1947-31 July 2020). The search aimed to identify original articles comparing IT with either Gamma3 nail or PFNA in patients with intertrochanteric fractures, with a specific focus on intraoperative and postoperative outcomes. Three strings were applied using the following search terms: intertrochanteric, gamma3, PFNA and PFNA II. The Boolean operators 'AND' and 'OR' were used, and all variations in spelling were included. Reference lists of selected articles were also searched to identify any other relevant studies.

\section{Eligibility criteria}

All articles published up to and including July 2020 were considered. Two independent reviewers (AD, MP) screened the abstracts and titles of articles identified through primary electronic search. Abstracts of eligible articles were obtained for assessment of inclusion criteria. Inclusion criteria were studies in the English language, publications from any country, human studies, studies on intertrochanteric fractures, intraoperative or postoperative outcomes assessed and IT compared with either Gamma3 or PFNA. All randomized controlled trials and both prospective and retrospective observational studies were included. Exclusion criteria were case reports, systematic reviews and meta-analyses, non-human studies, studies in non-English languages, studies not assessing outcomes and studies evaluating only sliding hip screw devices.

\section{Assessment of quality of studies}

Full text articles were obtained of all included studies and were screened by two independent reviewers (AD, MP) for quality. All studies were evaluated using the quality assessment of case-control series screening tool from the National Heart, Lung and Blood Institute [10]. All studies were assessed using this tool's nine-point criteria, and a study's quality rating was graded as good, fair or poor based on total score.

\section{Outcome measures}

Data on both intraoperative and postoperative outcomes were extracted from the included articles. Data included study characteristics (year of publication, sample size, length of follow-up), patient characteristics, intraoperative data (fluoroscopy time, operation time, blood loss), Harris Hip Score (HHS), time to union, periprosthetic fractures, implant failures, delayed union or nonunion and postoperative outcomes (pain, length of stay in hospital and complications). HHS is a clinical score that evaluates different methods of treatment by looking at pain, function, absence of deformity and range of motion, with the results being interpreted as follows: $<70=$ poor, $70-80=$ fair, $80-90=$ good and $90-100=$ excellent $[11]$.

\section{Results}

\section{Study characteristics}

Initial electronic searches identified 2625 articles, of which 14 were eligible for inclusion in this study (Figure 1). All the studies scored 'good' on the National Heart, Lung and Blood Institute criteria and were thus included for the scope of this review. Together, the included papers had data on a total of 3104 patients undergoing surgery for intertrochanteric fractures, of which 2683 were available for follow-up and assessment of postoperative outcomes. Ten studies were retrospective case series, two studies were prospective case series and two were randomized controlled trials (Table 1). The mean age of patients in the included studies was 73.3 years, and the average follow-up time was 25.0 months.

\section{Intraoperative outcomes}

Intraoperative outcomes reported in the studies included fluoroscopy time $(\mathrm{n}=1104)$, operation time $(\mathrm{n}=2086)$ and blood loss $(n=1633)$ (Table 2). Five studies reported fluoroscopy time, out of which three found that IT took 


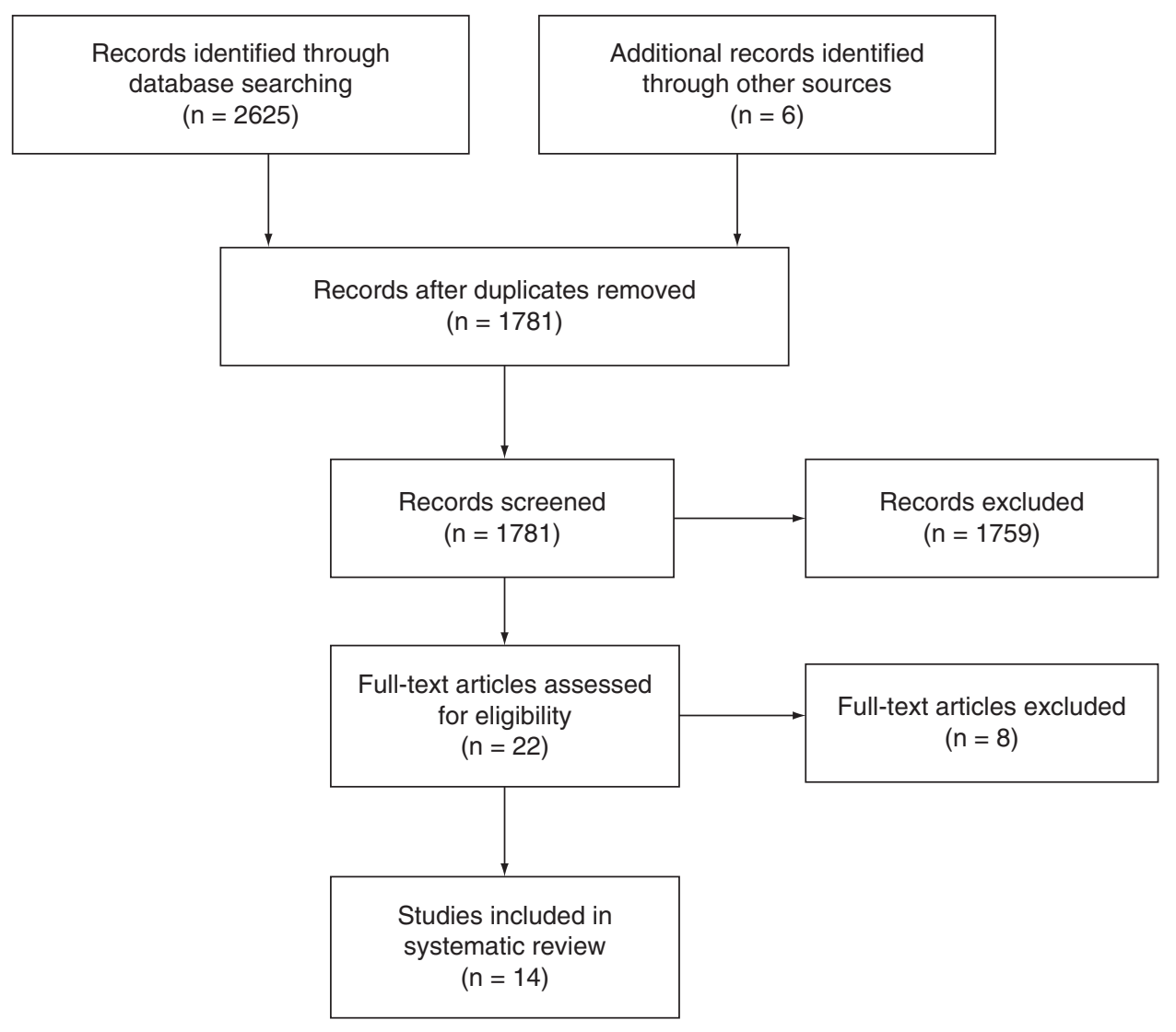

Figure 1. PRISMA chart.

statistically significantly longer than PFNA ( $\mathrm{p}<0.001 ; \mathrm{p}<0.05$; $\mathrm{p}<0.001)$ [12-14]. Seyhan et al. did not find significance $(\mathrm{p}=0.749)$ between IT and PFNA fluoroscopy times [15]. Wu et al. found that IT also had greater fluoroscopy time than Gamma3 ( $\mathrm{p}=0.012)[16]$.

Six studies compared differences in operating time between IT and PFNA, and four compared IT with Gamma3. Three out of the six studies reported that the IT cohort had a significantly longer operation time compared with PFNA ( $<<0.001 ; \mathrm{p}<0.001 ; \mathrm{p}<0.05$ ) [12-14]. Of studies looking at Gamma3, two found that IT had a significantly longer operation time compared with Gamma3 $(p=0.044 ; p=0.011)[16,17]$. By contrast, one study found Gamma3 had a significantly longer operation time ( $\mathrm{p}=0.034)[18]$.

Five studies $[12-14,19,20]$ reported the impact of IT compared with PFNA on blood loss, and three [16-18] compared IT with Gamma3. Three studies reported that patients with IT had significantly increased blood loss compared with those with PFNA ( $<<0.001 ; \mathrm{p}<0.05 ; \mathrm{p}=0.012$ ) [12-14]. Two studies found that IT had less blood loss than Gamma3, although only one found this significant $(\mathrm{p}=0.025)[17,18]$.

\section{Postoperative outcomes}

Harris Hip Score

Twelve studies reported HHS $(\mathrm{n}=2038)$ in patients, of which eight compared IT with PFNA and one compared IT with Gamma3 (Table 3). Two studies found that IT had a significantly higher HHS compared with PFNA $(\mathrm{p}<0.001 ; \mathrm{p}=0.038)[14,21]$. There was no significant difference in HHS reported between patients treated with IT compared with PFNA or Gamma3 in the remaining studies.

\section{Time to union}

With regard to time to union, three studies compared IT with PFNA, and one study compared IT with Gamma3 $(\mathrm{n}=556)$ (Table 4). There was no statistically significant difference reported in the time to union between IT and PFNA or Gamma3. 
Table 1. Study characteristics of included studies.

\begin{tabular}{|c|c|c|c|c|c|c|c|c|}
\hline Study (year) & Study design & $\begin{array}{l}\text { Devices } \\
\text { compared }\end{array}$ & Patients (n) & Followed up (n) & $\begin{array}{l}\text { Mean follow-up } \\
\text { time (months) }\end{array}$ & $\begin{array}{l}\text { Mean } \\
\text { age (years) }\end{array}$ & $\begin{array}{l}\text { Male patients } \\
(\%)\end{array}$ & Ref. \\
\hline Wu et al. (2014) & Retrospective & IT and Gamma3 & 261 & 261 & 12.0 & 72.0 & 23.9 & [16] \\
\hline Yu et al. (2016) & Retrospective & IT and PFNA & 176 & 147 & 20.0 & 74.5 & 45.5 & [13] \\
\hline $\begin{array}{l}\text { Serrano } \\
\text { et al. (2017) }\end{array}$ & Retrospective & IT and Gamma3 & 463 & 463 & 12.0 & 76.0 & 33.0 & [25] \\
\hline $\begin{array}{l}\text { Makki } \\
\text { et al. (2015) }\end{array}$ & Retrospective & IT and PFNA & 58 & 58 & $\mathrm{NA}^{\dagger}$ & 79.0 & 30.0 & [22] \\
\hline $\begin{array}{l}\text { Hopp } \\
\text { et al. (2016) }\end{array}$ & Prospective & IT and Gamma3 & 78 & 60 & 5.9 & 81.7 & 33.3 & [17] \\
\hline $\begin{array}{l}\text { Duramaz } \\
\text { et al. (2019) }\end{array}$ & Retrospective & IT and PFNA & 303 & 303 & 12 & 61.3 & 43.6 & [14] \\
\hline $\begin{array}{l}\text { Zehir } \\
\text { et al. (2015) }\end{array}$ & Retrospective & IT and PFNA & 276 & 265 & 16.0 & 77.0 & 38.4 & [12] \\
\hline $\begin{array}{l}\text { Imerci } \\
\text { et al. (2018) }\end{array}$ & Retrospective & IT and PFNA & NA & 69 & 12.0 & 56.3 & 60.9 & [23] \\
\hline $\begin{array}{l}\text { Seyhan } \\
\text { et al. (2015) }\end{array}$ & Prospective & IT and PFNA & 88 & 75 & 12.0 & 75.7 & 25.3 & [15] \\
\hline $\begin{array}{l}\text { Hui Zhang } \\
\text { et al. (2017) }\end{array}$ & Retrospective & IT and PFNA & 283 & 239 & 38.8 & 76.1 & 58.9 & [19] \\
\hline $\begin{array}{l}\text { Hui Zhang } \\
\text { et al. (2017) (2) }\end{array}$ & Retrospective & IT and PFNA & 243 & 174 & 40 & 73.0 & 36.7 & [21] \\
\hline Su et al. (2016) & $\begin{array}{l}\text { Randomized } \\
\text { controlled trial }\end{array}$ & IT and Gamma3 & 100 & 86 & 12 & 70.7 & 40.0 & {$[18]$} \\
\hline $\begin{array}{l}\text { Berger-Groch } \\
\text { et al. (2016) }\end{array}$ & $\begin{array}{l}\text { Randomized } \\
\text { controlled trial }\end{array}$ & IT and Gamma3 & 104 & 33 & 60 & 81.2 & 23.1 & [24] \\
\hline $\begin{array}{l}\text { Chi Zhang } \\
\text { et al. (2018) }\end{array}$ & Retrospective & IT and PFNA & 417 & 326 & 43.3 & 72.3 & 46.0 & [20] \\
\hline
\end{tabular}

\section{Delayed union, malunion and nonunion}

Six studies compared the number of cases of delayed union, malunion or nonunion between IT and PFNA $(n=852)$ (Table 5). Zhang et al. reported the number of cases of delayed union, malunion and nonunion and found that there was no statistically significant difference between IT and PFNA across all three groups [21]. Similarly, three studies looking at nonunion rates found no significant difference between IT and PFNA groups [15,22,23]. Two studies looked at IT compared with Gamma3, with no significant difference found in rates of nonunion [16,17].

Pain

Seven studies looked at hip and thigh pain experienced postoperatively by patients $(\mathrm{n}=1469)$, four comparing IT and PFNA and three comparing IT and Gamma3 (Table 6). Two studies reported that patients receiving IT had significantly lower postoperative hip and thigh pain compared with the PFNA group $(p=0.019 ; p=0.043)[13,21]$. Duramaz and İlter found that a greater percentage of patients with IT experienced pain compared with those with PFNA (29.1 vs $20.0 \%$ ), although statistical significance was not assessed [14].

Two of the studies comparing the percentage of patients experiencing postoperative pain in IT and Gamma3 groups found no statistically significant difference $[16,18]$. Hopp et al. reported postoperative pain using a visual analog scale and found that there was no significant difference between the IT and Gamma3 groups ( $p=0.169)$ [17].

Length of hospital stay

Six studies reported the length of time the patient spent in the hospital $(\mathrm{n}=1170)$; three studies compared IT with PFNA, and three studies compared IT with Gamma3 (Table 7). Yu et al. found that patients with PFNA had a significantly shorter length of time in the hospital compared with the IT group $(p<0.05)$ [13], whereas the other two studies reported no significant difference between these groups [12,19]. Berger-Groch et al. found a statistically significant shorter length of hospital stay for Gamma3 patients compared with IT patients ( $p=0.03$ ) [24], although there was no significant difference between these groups in the other two studies $[16,17]$. 
Table 2. Impact of InterTAN and PFNA or Gamma3 on intraoperative outcomes of fluoroscopy time $(n=1104)$, operation time $(n=2086)$ and blood loss $(n=1633)$.

\begin{tabular}{|c|c|c|c|c|c|c|}
\hline Study (year) & Patients (n) & Mean age (years) & InterTAN & PFNA & p-value & Ref. \\
\hline Fluoroscopy time & & & $\begin{array}{l}\text { Fluoroscopy time } \\
\text { (mins) }\end{array}$ & $\begin{array}{l}\text { Fluoroscopy time } \\
\text { (mins) }\end{array}$ & & \\
\hline Zehir et al. (2015) & 276 & 77.0 & 2.0 & 1.5 & $<0.001^{\ddagger}$ & [12] \\
\hline Yu et al. (2016) & 176 & 74.5 & 5.0 & 2.8 & $<0.05$ & [13] \\
\hline Seyhan et al. (2015) & 88 & 75.7 & 1.0 & 1.1 & 0.749 & [15] \\
\hline Wu et al. (2014) & 261 & 72.0 & 2.9 & $2.6^{\dagger}$ & 0.012 & [16] \\
\hline Duramaz et al. (2019) & 303 & 61.3 & 34.6 & 29.9 & $<0.001^{\S}$ & [14] \\
\hline Operation time & & & Operation time (mins) & Operation time (mins) & & \\
\hline Zehir et al. (2015) & 276 & 77.0 & 55.4 & 44.4 & $<0.001^{\ddagger}$ & [12] \\
\hline Yu et al. (2016) & 176 & 74.5 & 71.9 & 52.3 & $<0.05$ & [13] \\
\hline Seyhan et al. (2015) & 88 & 75.7 & 73.9 & 73.0 & 0.721 & [15] \\
\hline Zhang et al. (2017) & 283 & 76.1 & 67.2 & 68.9 & 0.848 & [19] \\
\hline Zhang et al. (2018) & 417 & 72.3 & 65.8 & 66.2 & 0.216 & [20] \\
\hline $\begin{array}{l}\text { Berger-Groch et al. } \\
\text { (2016) }\end{array}$ & 104 & 81.2 & 48.0 & $51.0^{\dagger}$ & 0.52 & [24] \\
\hline Hopp et al. (2016) & 78 & 81.7 & 78.0 & $64.6^{\dagger}$ & 0.044 & [17] \\
\hline Su et al. (2016) & 100 & 70.1 & 52.3 & $66.7^{\dagger}$ & 0.034 & [18] \\
\hline Wu et al. (2014) & 261 & 72.0 & 63.7 & $59.9^{\dagger}$ & 0.011 & [16] \\
\hline Duramaz et al. (2019) & 303 & 61.3 & 61.6 & 52.5 & $<0.001^{\S}$ & [14] \\
\hline Blood loss & & & Blood loss (ml) & Blood loss (ml) & & \\
\hline Zehir et al. (2015) & 276 & 77.0 & 211.4 & 139.7 & $<0.001^{\ddagger}$ & [12] \\
\hline Yu et al. (2016) & 176 & 74.5 & 190.6 & 180.9 & $<0.05$ & [13] \\
\hline Zhang et al. (2017) & 283 & 76.1 & 180.7 & 185.1 & 0.078 & [19] \\
\hline Zhang et al. (2018) & 417 & 72.3 & 198.9 & 199.4 & 0.092 & [20] \\
\hline Hopp et al. (2016) & 78 & 81.7 & 168.1 & $175.7^{\dagger}$ & 0.915 & [17] \\
\hline Su et al. (2016) & 100 & 70.1 & 80.3 & $130.6^{\dagger}$ & 0.025 & [18] \\
\hline Duramaz et al. (2019) & 303 & 61.3 & 204.2 & 196.9 & 0.012 & [14] \\
\hline Wu et al. (2014) & 261 & 72.0 & 87 & $86^{\dagger}$ & 0.181 & [16] \\
\hline \multicolumn{7}{|c|}{$\begin{array}{l}\text { Bold font indicates } p \text {-values with statistical significance. } \\
\text { † Gamma3 nail. } \\
\text { †Includes comparison of InterTAN with both PFNA and Talon }{ }^{\top M} \text { lag screw. } \\
\text { §Includes comparison of InterTAN with both PFNA and Profin }{ }^{\circledR} \text {. } \\
\text { PFNA: Proximal femoral nail antirotation. }\end{array}$} \\
\hline
\end{tabular}

\section{Periprosthetic fracture}

Five studies looked at periprosthetic fractures with IT and PFNA, and one compared IT and Gamma3 (n = 1312) (Table 8). Wu et al. found a significantly greater number of femoral shaft fractures in the Gamma3 group than the IT group ( $p=0.044)$ [16]. Yu et al. found a significantly higher number of lateral cortex fractures in patients treated with IT compared with PFNA ( $p=0.045)$ [13]. However, of the remaining four studies comparing IT and PFNA, three found a significantly greater periprosthetic fracture incidence with PFNA than IT [15,19-21]. Zhang et al. did not specify fracture type; however, they did report a greater periprosthetic fracture rate in the PFNA group $(\mathrm{p}=0.004)[20]$.

\section{Implant failures}

There were seven studies that looked at implant failures in IT and PFNA groups and four studies comparing IT with Gamma3 ( $\mathrm{n}=2081$ ) (Table 9). Some studies categorized type of failure by group, such as cut-out or lateral screw migration, whereas others did not specify implant failure type. Six studies [12,13,19,21-23] assessed cut-out between IT and PFNA, and four found that PFNA had a significantly higher number of cases compared with IT $(p=0.024 ; p=0.033 ; p=0.01 ; p<0.001)[12,13,19,22]$. Three studies [13,21,23] reported screw migration; two studies $[13,21]$ found no statistically significant difference, whereas the remaining study found a significantly higher number of cases in the PFNA group compared with IT $(p=0.008)$ [12]. Furthermore, Imerci et al. found that 
Table 3. Impact of InterTAN and PFNA or Gamma3 on HHS $(n=2038)$.

\begin{tabular}{|c|c|c|c|c|c|c|c|c|}
\hline Study (year) & $\begin{array}{l}\text { Total patients } \\
\text { (n) }\end{array}$ & $\begin{array}{l}\text { Patients } \\
\text { followed up (n) }\end{array}$ & $\begin{array}{l}\text { Mean age } \\
\text { (years) }\end{array}$ & $\begin{array}{l}\text { Mean follow-up } \\
\text { time (months) }\end{array}$ & HHS, InterTAN & HHS, PFNA & p-value & Ref. \\
\hline $\begin{array}{l}\text { Imerci et al. } \\
(2018)\end{array}$ & NA & 69 & 56.3 & 12.0 & 82.6 & 79.8 & 0.294 & [23] \\
\hline $\begin{array}{l}\text { Hui Zhang et al. } \\
\text { (2017) (2) }\end{array}$ & 243 & 174 & 73 & 40 & 75.1 & 71.0 & $<0.001$ & [21] \\
\hline $\begin{array}{l}\text { Chi Zhang et al. } \\
\text { (2018) }\end{array}$ & 417 & 326 & 72.3 & 43.3 & 80.2 & 79.7 & 0.187 & [20] \\
\hline $\begin{array}{l}\text { Berger-Groch et } \\
\text { al. (2016) }\end{array}$ & 104 & 33 & 81.2 & 60 & 69.6 & $70.4^{\dagger}$ & 0.84 & [24] \\
\hline Su et al. (2016) & 100 & 86 & 70.7 & 12 & 63.3 & $64.7^{\dagger}$ & 0.136 & [18] \\
\hline $\begin{array}{l}\text { Duramaz et al. } \\
\text { (2019) }\end{array}$ & 303 & 303 & 61.3 & 12 & 75.2 & 76.8 & $0.038^{\S}$ & [14] \\
\hline Wu et al. (2014) & 261 & 261 & 72.0 & 12 & 88.2 & $85.6^{\dagger}$ & 0.076 & [16] \\
\hline $\begin{array}{l}\text { Bold font indicates } \\
\text { † Gamma3 nail. } \\
\text { †Includes compari } \\
\text { \$Includes compari } \\
\text { HHS: Harris Hip Sc }\end{array}$ & $\begin{array}{l}\text {-values with stati } \\
\text { n of InterTAN wit } \\
\text { n of InterTAN wit } \\
\text { e; NA: Not applic }\end{array}$ & $\begin{array}{l}\text { al significance. } \\
\text { oth PFNA and Talor } \\
\text { oth PFNA and Profi } \\
\text {; PFNA: Proximal fe }\end{array}$ & M lag screw. & & & & & \\
\hline
\end{tabular}

\begin{tabular}{|c|c|c|c|c|c|c|c|c|}
\hline Study (year) & $\begin{array}{l}\text { Total patients } \\
\text { (n) }\end{array}$ & $\begin{array}{l}\text { Patients } \\
\text { followed up (n) }\end{array}$ & $\begin{array}{l}\text { Mean age } \\
\text { (years) }\end{array}$ & $\begin{array}{l}\text { Mean follow-up } \\
\text { time (months) }\end{array}$ & $\begin{array}{l}\text { InterTAN, n } \\
\text { (weeks) }\end{array}$ & PFNA (weeks) & p-value & Ref. \\
\hline $\begin{array}{l}\text { Seyhan et al. } \\
\text { (2015) }\end{array}$ & 88 & 75 & 75.7 & 12.0 & 9.9 & 9.79 & 0.871 & [15] \\
\hline $\begin{array}{l}\text { Imerci et al. } \\
(2018)\end{array}$ & NA & 69 & 56.3 & 12.0 & 17.1 & 17.8 & 0.573 & [23] \\
\hline $\begin{array}{l}\text { Chi Zhang et al. } \\
\text { (2018) }\end{array}$ & 417 & 326 & 72.3 & 43.3 & 14.8 & 15.2 & NA & [20] \\
\hline
\end{tabular}

PFNA patients had a significantly greater reported incidence of shaft fractures, cut-out and lateral migration screw $(\mathrm{p}=0.0001)[23]$.

Two studies compared cut-out on its own between IT and Gamma3, with one study finding significantly more cases in the Gamma3 cohort $(\mathrm{p}=0.024)$ [16]. Serrano et al. reported that there was a significantly higher number of cut-outs and 'catastrophic failures' in the Gamma3 group compared with the IT group $(p=0.007)$ [25]. Hopp et al. reported no significant difference between the IT and Gamma3 groups with regard to secondary dislocation with cut-out and secondary varus collapse without cut-out $(\mathrm{p}=0.466)[17]$.

\section{Other complications}

A variety of generic complications were reported by studies and are described here in brief. No studies comparing IT and PFNA found statistical significance in the incidence of postoperative complications [12,15,22]. Zehir et al. found no significant differences in pneumonia, pressure ulcers, urinary tract infections, decompensated heart failure, pulmonary embolism, deep vein thrombosis, hematoma or deep and superficial wound infections [12]. Seyhan et al. 
Table 5. Impact of InterTAN and PFNA on number of cases of delayed union, malunion and nonunion ( $\mathrm{n}=852$ ).

\begin{tabular}{|c|c|c|c|c|c|c|c|c|c|}
\hline Study (year) & $\begin{array}{l}\text { Total patients } \\
\text { (n) }\end{array}$ & $\begin{array}{l}\text { Patients } \\
\text { followed up } \\
\text { (n) }\end{array}$ & $\begin{array}{l}\text { Mean } \\
\text { age (years) }\end{array}$ & $\begin{array}{l}\text { Mean } \\
\text { follow-up } \\
\text { time (months) }\end{array}$ & Complication & $\begin{array}{l}\text { InterTAN, n } \\
\text { (cases) }\end{array}$ & PFNA, n (cases) & p-value & Ref. \\
\hline \multirow{3}{*}{$\begin{array}{l}\text { Hui Zhang et } \\
\text { al. (2017) }\end{array}$} & 283 & 329 & 76.1 & 38.8 & Delayed union & 4 & 5 & 0.709 & [19] \\
\hline & & & & & Malunion & 2 & 0 & 0.498 & \\
\hline & & & & & Nonunion & 2 & 0 & 0.498 & \\
\hline $\begin{array}{l}\text { Makki et al. } \\
\text { (2015) }\end{array}$ & 58 & 58 & 79 & $\mathrm{NA}^{\dagger}$ & Nonunion & 2 & 11 & 0.1 & [22] \\
\hline $\begin{array}{l}\text { Seyhan et al. } \\
\text { (2015) }\end{array}$ & 88 & 75 & 74.5 & 12.0 & Nonunion & 0 & 0 & NA & [15] \\
\hline $\begin{array}{l}\text { Hopp et al. } \\
(2016)\end{array}$ & 78 & 60 & 81.7 & 5.9 & Nonunion & 3 & $3^{\ddagger}$ & 0.473 & [17] \\
\hline $\begin{array}{l}\text { Imerci et al. } \\
(2018)\end{array}$ & 69 & 69 & 56.25 & 12 & Nonunion & 1 & 1 & NA & [23] \\
\hline $\begin{array}{l}\text { Wu et al. } \\
\text { (2014) }\end{array}$ & 261 & 261 & 72.0 & 12 & Nonunion & 1 & $5^{\ddagger}$ & 0.381 & [16] \\
\hline \multicolumn{10}{|c|}{$\begin{array}{l}\text { Bold font indicates } p \text {-values with statistical significance. } \\
\dagger \text { Variable: patients were followed up until satisfactory union. } \\
\text { ‡Gamma3 nail. } \\
\text { NA: Not applicable; PFNA: Proximal femoral nail antirotation. }\end{array}$} \\
\hline
\end{tabular}

Table 6. Impact of InterTAN compared with PFNA on postoperative pain $(n=1469)$.

\begin{tabular}{|c|c|c|c|c|c|c|}
\hline Study (year) & Patients (n) & Mean age (years) & $\begin{array}{l}\text { InterTAN patients } \\
\text { reporting } \\
\text { postoperative } \\
\text { pain }(\%)\end{array}$ & $\begin{array}{l}\text { PFNA patients } \\
\text { reporting } \\
\text { postoperative pain } \\
(\%)\end{array}$ & p-value & Ref. \\
\hline Zehir et al. (2015) ${ }^{\dagger}$ & 276 & 77.0 & 4.9 & 10.4 & $0.57^{\ddagger}$ & [12] \\
\hline Yu et al. (2016) ${ }^{\dagger}$ & 176 & 74.5 & 4.8 & 11.6 & 0.019 & [13] \\
\hline $\begin{array}{l}\text { Hui Zhang et al. } \\
(2017)^{\dagger}\end{array}$ & 283 & 75.7 & 3.5 & 9.4 & 0.043 & [19] \\
\hline Su et al. $(2016)^{\dagger}$ & 92 & 70.7 & 6.4 & $8.9^{\S}$ & 0.650 & [18] \\
\hline Wu et al. (2014) ${ }^{\dagger}$ & 261 & 72.0 & 4.6 & $4.0^{\S}$ & NA & [16] \\
\hline $\begin{array}{l}\text { Duramaz et al. } \\
(2019)^{\dagger}\end{array}$ & 303 & 61.3 & 29.1 & 20.0 & NA & [14] \\
\hline Hopp et al. (2016) & 78 & 81.7 & 4.07 & $4.88^{\S}$ & 0.169 & [17] \\
\hline
\end{tabular}

Bold font indicates p-values with statistical significance.

$\dagger$ Pain in hip or thigh region reported postoperatively; scoring system not mentioned.

$¥$ Includes comparison of InterTAN with both PFNA and Talon ${ }^{T M}$ lag screw.

$\S$ Gamma3 nail.

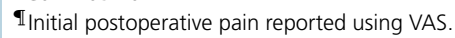

NA: Not applicable; PFNA: Proximal femoral nail antirotation; VAS: Visual analog scale.

\section{Table 7. Impact of InterTAN and PFNA or Gamma3 on length of hospital stay $(n=1170)$.}

\begin{tabular}{|c|c|c|c|c|c|c|}
\hline Study (year) & Patients (n) & Mean age (years) & $\begin{array}{l}\text { InterTAN hospital } \\
\text { stay (days) }\end{array}$ & $\begin{array}{l}\text { PFNA hospital } \\
\text { stay (days) }\end{array}$ & p-value & Ref. \\
\hline $\begin{array}{l}\text { Hui Zhang et al. } \\
\text { (2017) }\end{array}$ & 283 & 76.1 & 11.9 & 11.67 & 0.21 & [19] \\
\hline Zehir et al. (2015) & 276 & 77 & 7.45 & 7.14 & $0.28^{\ddagger}$ & [12] \\
\hline Yu et al. (2016) & 168 & 74.5 & 9.65 & 8.58 & $<0.05$ & [13] \\
\hline $\begin{array}{l}\text { Berger-Groch et al. } \\
\text { (2016) }\end{array}$ & 104 & 81.2 & 11.6 & $10.3^{\dagger}$ & 0.03 & [24] \\
\hline Hopp et al. (2016) & 78 & 81.7 & 16.5 & $17.8^{\dagger}$ & 0.64 & [17] \\
\hline Wu et al. (2014) & 261 & 72.0 & 10.8 & $11.1^{\dagger}$ & 0.081 & [16] \\
\hline
\end{tabular}

Bold font indicates $\mathrm{p}$-values with statistical significance.

† Gamma3 nail.

¥Includes comparison of IT with both PFNA and Talon ${ }^{T M}$ lag screw.

PFNA: Proximal femoral nail antirotation. 
Table 8. Impact of InterTAN and PFNA on number of reported cases of secondary periprosthetic fracture $(n=1312)$.

\begin{tabular}{|c|c|c|c|c|c|c|c|c|c|}
\hline Study (year) & $\begin{array}{l}\text { Total patients } \\
\text { (n) }\end{array}$ & $\begin{array}{l}\text { Patients } \\
\text { followed up } \\
\text { (n) }\end{array}$ & $\begin{array}{l}\text { Mean age } \\
\text { (years) }\end{array}$ & $\begin{array}{l}\text { Mean } \\
\text { follow-up } \\
\text { time (months) }\end{array}$ & $\begin{array}{l}\text { Fracture } \\
\text { description }\end{array}$ & InterTAN & PFNA & $p$-value & Ref. \\
\hline Yu et al. (2016) & 168 & 147 & 74.5 & 20.0 & Lateral cortex & 8 & 1 & 0.045 & [13] \\
\hline $\begin{array}{l}\text { Seyhan et al. } \\
\text { (2015) }\end{array}$ & & & & & Lateral cortex & 0 & 1 & NA & \\
\hline $\begin{array}{l}\text { Chi Zhang } \\
\text { et al. (2018) }\end{array}$ & 417 & 326 & 72.3 & 43.3 & NA & 7 & 22 & 0.004 & [20] \\
\hline $\begin{array}{l}\text { Wu et al. } \\
\text { (2014) }\end{array}$ & 261 & 261 & 72.0 & 12 & Femoral shaft & 1 & $10^{\dagger}$ & 0.044 & [16] \\
\hline \multirow[t]{2}{*}{$\begin{array}{l}\text { Hui Zhang et } \\
\text { al. (2017) (2) }\end{array}$} & 243 & 174 & 73 & 40 & Periprosthetic & 0 & 1 & 1.000 & [21] \\
\hline & & & & & Lateral cortex & 0 & 7 & 0.022 & \\
\hline
\end{tabular}

found no significant difference in the number of cases of hematomas between IT and PFNA [15]. Makki et al. reported no significant difference in the number of cases of wound infections between IT and PFNA [22].

Of studies looking at Gamma3 and IT, only the investigation by Berger-Groch et al. found a significantly higher number of complications in Gamma3 patients compared with IT patients $(p=0.04)$; these included pneumonia, urinary tract infections, acute kidney failure, hyperglycemic crisis, wound hematoma, wound infection and positional damage [24]. Hopp et al. found no statistically significant difference between complication rate in IT patients compared with Gamma3 patients with regard to pulmonary and urinary tract infections $(\mathrm{p}=0.797)$ or hematomas ( $\mathrm{p}=0.423)$; however, local surgical debridement was needed in one case in the Gamma3 group [17]. Su et al. found no significant difference in pulmonary embolism ( $\mathrm{p}=0.558)$ or deep vein thrombosis $(\mathrm{p}=0.461)$ between IT and Gamma3 patients [18]. Wu et al. found no significant difference in deep vein thrombosis $(\mathrm{p}=0.695)$, wound hematoma $(\mathrm{p}=0.157)$ or urinary tract infection $(\mathrm{p}=0.828)[16]$.

\section{Discussion}

This systematic review aimed to compare the clinical and radiological outcomes of IT compared with two popular single nail systems, PFNA and Gamma3, in the treatment of intertrochanteric fractures. The authors acknowledge that there are other devices for treating these fractures, including Aesculap ${ }^{\circledR}$ (PA, USA) Targon ${ }^{\circledR}$ (Braun, Germany) PFT and Orthofix Veronail ${ }^{\circledR}$ (TX, USA) which were outside the scope of this review. The authors found that IT was superior to PFNA and Gamma3, with lower implant-related complications of cut-out and screw migration, lower incidence of secondary periprosthetic fractures and less postoperative pain. No differences were found in HHS, time to union or cases of nonunion or malunion. Intraoperatively, both single-screw devices required less fluoroscopy time than IT. Although PFNA had more favorable outcomes in operative time and blood loss than IT, a clear advantage was not seen with Gamma3. PFNA and Gamma3 patients were also shown in some studies to have a lower length of postoperative hospital stay compared with IT.

Intraoperative parameters demonstrated shorter fluoroscopy time using single-screw devices and lower operating times and blood loss using PFNA versus IT. The dual-screw design of IT, which requires placement of an additional screw, may explain the greater fluoroscopy and operating times. Increased blood loss could be directly linked to longer operating times with IT or result from additional drilling for the second screw. However, Seyhan et al. indicate the most time-consuming part of the IT operation to be determining a correct entry point [15]. Furthermore, Wu et al. report that the IT device is more challenging to insert into smaller bone cavities because of its trapezoidal proximal nail end; the increased manipulation during this process could explain the increased intraoperative and fluoroscopy time and blood loss [16]. Despite the favorable intraoperative parameters of PFNA and Gamma3, which may influence the surgeon's decision on fixation device, it is important to note that intraoperative outcomes should be viewed within a wider context, alongside longer-term parameters. The absolute values for intraoperative 


\begin{tabular}{|c|c|c|c|c|c|c|c|c|c|}
\hline Study (year) & $\begin{array}{l}\text { Total patients } \\
\text { (n) }\end{array}$ & $\begin{array}{l}\text { Patients } \\
\text { followed up } \\
\text { (n) }\end{array}$ & $\begin{array}{l}\text { Mean } \\
\text { age (years) }\end{array}$ & $\begin{array}{l}\text { Mean } \\
\text { follow-up } \\
\text { time (months) }\end{array}$ & Failure type & $\begin{array}{l}\text { InterTAN cases } \\
\text { (n) }\end{array}$ & PFNA cases $(n)$ & $\mathrm{p}$-value & Ref. \\
\hline $\begin{array}{l}\text { Hui Zhang } \\
\text { et al. (2017) (2) }\end{array}$ & 243 & 174 & 73 & 40 & Cut-out & 1 & 2 & 1.000 & [21] \\
\hline \multirow[t]{3}{*}{ Yu et al. (2016) } & 168 & 147 & 74.5 & 20 & Generic $\ddagger$ & 3 & 1 & 0.641 & [13] \\
\hline & & & & & Cut-out & 0 & 6 & 0.033 & \\
\hline & & & & & $\begin{array}{l}\text { Lateral screw } \\
\text { migration }\end{array}$ & 1 & 1 & 1.000 & \\
\hline $\begin{array}{l}\text { Serrano et al. } \\
\text { (2017) }\end{array}$ & 413 & 413 & 76 & 12 & $\begin{array}{l}\text { Cut-out and } \\
\text { generic }{ }^{\ddagger}\end{array}$ & 1 & $9^{\dagger}$ & 0.007 & [25] \\
\hline \multirow[t]{2}{*}{$\begin{array}{l}\text { Zehir et al. } \\
\text { (2015) }\end{array}$} & 276 & 265 & 77 & 16.0 & Cut-out & 0 & 8 & $<0.001^{\S}$ & [12] \\
\hline & & & & & $\begin{array}{l}\text { Screw } \\
\text { migration }\end{array}$ & 0 & 5 & $0.008^{\S}$ & \\
\hline \multirow[t]{2}{*}{$\begin{array}{l}\text { Hopp et al. } \\
\text { (2016) }\end{array}$} & 78 & 60 & 81.7 & 5.9 & $\begin{array}{l}\text { Secondary } \\
\text { dislocation } \\
\text { with cut-out }\end{array}$ & 2 & $1^{\dagger}$ & 0.466 & [17] \\
\hline & & & & & $\begin{array}{l}\text { Secondary } \\
\text { varus collapse } \\
\text { (no cut-out) }\end{array}$ & 2 & $3^{\dagger}$ & & \\
\hline
\end{tabular}

parameters (Table 2) remain within reasonable clinical limits for the IT group and may be acceptable in light of better long-term fixation outcomes.

The findings from this review suggest that IT has several superior postoperative fixation outcomes compared with single-screw devices. Wu et al. and Zhang et al. reported significantly higher rates of femoral shaft fractures with PFNA and Gamma3 nails [16,19,21]. Femoral fractures occur at the tip of the nail insertion into the femoral shaft [23] and as a result of poor contact with the intramedullary wall [13]. IT has a tapered design that is hypothesized to reduce the concentration of stress around the nail tip, thereby reducing the risk of femoral fracture [19]. Additionally, Zhang et al. found on revision surgery that looseness of distal locking screws can contribute to femoral shaft fractures [19]. The results with regard to lateral cortex fractures were inconclusive, with Zhang et al. reporting higher rates of lateral cortex fractures in the PFNA group $(\mathrm{p}=0.044)[19]$ and $\mathrm{Yu}$ et al. finding higher rates in the IT group $(\mathrm{p}=0.045)[13]$.

Furthermore, screw migration was noted in some studies to be lower in IT patients compared with PFNA patients $[12,23]$. Several features of the IT design may provide resistance to screw migration, including superior fracture compression and a larger screw diameter compared with PFNA; Seyhan et al. also suggested that superior IT compression reduces screw migration [15]. Notably, there are a limited number of studies in the literature 
comparing screw migration rates between IT and Gamma3. The incidence of cut-out is also lower with IT compared with PFNA and Gamma3. Takigami et al. established several factors that influence the risk of cut-out: implant position, tip-to-apex distance (TAD), fracture reduction and time to weight-bearing [26]. The dual-screw design of IT is thought to provide better rotational stability and resist excess load upon weight-bearing compared with single-screw devices, thus reducing the risk of cut-out $[12,13]$. There are, however, fracture-related factors that can also determine cut-out rates; Gavaskar et al. emphasized the importance of categorizing fractures based on AO classification, as complication rates are higher in complicated fractures [27]. Seyhan et al. also noted that the skill of the surgeon impacted cut-out, with higher rates in inexperienced surgeons [15]. Cut-out rates have been shown to decrease as a result of learning curve in other long-term studies [24]. The variability in surgical experience across the studies was not documented and is therefore a limitation of this study.

Although IT appears to demonstrate favorable implant failure outcomes compared with PFNA and Gamma3, it is difficult to draw valid conclusions from the authors' data, and there is a need for longer-term follow-up in future studies. Although Serrano et al. demonstrated significantly higher rates of implant failure with Gamma3 $(\mathrm{p}=0.007)$ [25], the difference in varus collapse was nonsignificant in the longer-term study by Hopp et al. [17]. Superior compression with IT may prevent uncontrolled shortening and subsequent varus collapse. In a review by Nherera et al., the authors suggest that intramedullary nail length could influence rates of implant failure [9], although Serrano et al. argue that shortening and varus collapse are due to proximal fixation and not nail length [25]. The researchers found that proximal femoral shortening over $5 \mathrm{~mm}$ led to worse functional outcomes in patients, although no acceptable cut-off has been determined in the literature. Zhang et al. report that factors associated with implant failure and subsequent surgical revision are early weight-bearing, inadequate intraoperative positioning and poor fracture reduction [19]. Surgical technique and postoperative protocol are important and perhaps overlooked factors that can greatly influence the effectiveness of intramedullary nails.

Additionally, IT patients show lower rates of postoperative pain compared with single-screw device patients. Zhang et al. attributed this to the distal bifurcation of the IT nail causing fewer perioperative fractures and, subsequently, reduced pain [19]. This may also contribute to lower rates of cut-out within the IT group [9]. Although $\mathrm{Su}$ et al. and Berger-Groch et al. found increased short-term pain in Gamma3-treated patients, 5-year follow-up revealed no significant differences in pain [18,24]. Notably, there was a high rate of loss to follow-up, which may affect interpretation of the results. Postoperative pain is a difficult outcome to assess and compare across studies because of the subjective nature of pain, variation in prescribed analgesia and different assessment tools used in studies. This leads to difficulty in drawing reliable conclusions on postoperative pain benefits with IT. Although postoperative outcomes in IT-treated patients were largely favorable, studies evaluating time to union and cases of malunion showed minimal differences between IT and PFNA and Gamma3 nails. Notably, the incidence of malunion and nonunion was low across studies and therefore may not have been sensitive in detecting significant differences.

Some studies in this review discussed the utility of TAD in determining postoperative complications in intertrochanteric fractures. Zhang et al. found no difference in TAD between failed and successful implant surgery [21]. The researchers found that only $87 \%$ of patients with radiological reduction had a TAD $<25 \mathrm{~mm}$, and patients with implant failure had a TAD $<19 \mathrm{~mm}$ [21]. TAD alone may be insufficient in predicting favorable outcomes, and the researchers suggest that bone quality may also impact the use of TAD [21]. A study by Nikoloski et al. argued that TAD $<25 \mathrm{~mm}$ was too generous, and that this should be revised to $<20 \mathrm{~mm}$ with PFNA to prevent axial migration [28]. A lower TAD limit is equally debated within the literature. A biomechanical study from Lenz et al. demonstrated no significant differences in number of cycles to failure between cadavers with normal $(20 \mathrm{~mm})$ and reduced $(6 \mathrm{~mm})$ TAD; however, the clinical relevance is yet to be determined [29]. Each intramedullary nailing system may have unique TAD requirements, as opposed to the one-size-fits-all approach used today. Although TAD is a useful parameter for predicting outcomes, further research is required to look at device-specific TAD and to identify if modified TAD criteria would be of benefit in select patient groups.

Choice of implant in patients with intertrochanteric fractures may also require consideration of bone quality. Many hip fractures are often associated with underlying osteoporosis, which can complicate surgery because of poor bone quality [19]. Zhang et al. hypothesized that there is a greater responsibility of the nail to support weightbearing in osteoporotic patients, as poorer quality bone is unable to effectively distribute load [19]. Osteoporosis can cause greater postoperative complications, such as cut-out and implant failure, because of microfractures introduced during surgery [19]. PFNA has been stipulated to be more effective in frail patients with multiple comorbidities [12] because of its favorable intraoperative parameters and ability to provide better compaction 
compared with IT [13]. Further studies are required to stratify osteoporotic patients by disease severity to determine optimum treatment in varying patient groups.

This study supports the work of Nherera $e t$ al. and Ma et al. evaluating the effectiveness of IT versus PFNA and Gamma3 nails $[9,30]$. However, the authors of this study recognize several limitations. The review included a relatively small sample size of just 14 studies, of which only five compared IT and Gamma3. There was study heterogeneity in patient demographics, anesthesia use, postoperative physiotherapy and study design. The majority of included studies were retrospective or prospective cohort studies, and there is a need for further high-level evidence in the literature. However, included papers were thoroughly screened and were deemed to be of high quality, therefore minimizing the impact of these limitations. Studies also showed variability in follow-up times, ranging from 6 months to 5 years, and greater follow-up is required to assess the long-term viability of internal fixation devices and their impact on quality of life. Furthermore, some studies did not stratify between stable and unstable intertrochanteric fractures. Although outside the remit of this review, another important factor to consider is the cost-effectiveness of IT compared with PFNA and Gamma3 nails.

\section{Conclusion}

The current literature suggests that there is no clear advantage of IT over PFNA and the Gamma3 nailing system. Although the use of IT demonstrated favorable outcomes with regard to postoperative pain, cut-out and screw migration, no differences were found in HHS and bone union. Intraoperative parameters of fluoroscopy time and operating time favored the single-screw devices over IT, with blood loss and length of hospital stay significantly lower in the PNFA group compared with the IT group. These findings can be used alongside clinical judgment to determine optimum treatment for patients. Further long-term randomized controlled trials are required to compare the benefits and drawbacks of IT versus other cephalomedullary nailing devices.

\section{Future perspective}

With life expectancy predicted to increase, hip fractures will remain a significant cause of morbidity and mortality in the aging population, and research must be conducted to optimize treatment strategies for this cohort. We propose a shift toward a 'tailor-made' strategy for separate patient groups, taking parameters such as bone quality and fracture pattern into account. Future studies may also wish to evaluate the utility of bone quality and TAD as predictive markers for specific postoperative complications. Research is also required to determine acceptable TAD ranges for individual nailing devices, as TAD is unlikely to be a one-size-fits-all solution. Finally, studies are required to evaluate the cost-effectiveness of different cephalomedullary devices.

\section{Executive summary}

- Hip fractures remain a significant cause of morbidity and mortality within healthcare systems, with an estimated global incidence of 1.6 million fractures annually.

- Certain subtypes of unstable intertrochanteric fractures are surgically treated with the use of intramedullary nailing devices.

- Assessment of clinical and radiological outcomes reveals no clear advantage of TRIGEN ${ }^{\top M}$ InterTAN $^{T M}$ (IT) over the single-screw proximal femoral nail antirotation (PFNA) and Gamma3 nailing system.

- The results of the study should be used in conjunction with clinical judgment to determine optimum treatment for patients requiring surgical treatment of hip fractures.

\section{Author contributions}

A Date contributed to conceptual design, methodology, original research, literature search, writing and review of the manuscript. M Panthula contributed to literature search, methodology, collating of results and writing of the manuscript. A Bolina contributed to data analysis and writing of the manuscript, with focus on the discussion.

\section{Financial \& competing interests disclosure}

The article may receive support for publication costs from Imperial College London. The authors have no other relevant affiliations or financial involvement with any organization or entity with a financial interest in or financial conflict with the subject matter or materials discussed in the manuscript apart from those disclosed.

No writing assistance was utilized in the production of this manuscript. 
Open access

This work is licensed under the Creative Commons Attribution 4.0 License. To view a copy of this license, visit http://creativecomm ons.org/licenses/by/4.0/

\section{References}

Papers of special note have been highlighted as: $\bullet$ of interest; $\bullet \bullet$ of considerable interest

1 Huette P, Abou-Arab O, Djebara AE et al. Risk factors and mortality of patients undergoing hip fracture surgery: a one-year follow-up study. Sci. Rep. (2020).

2 Svedbom A, Hernlund E, Ivergård M et al. Osteoporosis in the European Union: a compendium of country-specific reports. Arch. Osteoporos. (2013).

3 National Hip Fracture Database (NHFD) annual report 2019, RCP London. www.rcplondon.ac.uk/projects/outputs/national-hip-fracture-database-nhfd-annual-report-2019

4 H.R. Mir GJH. Intertrochanteric femur fractures. In: Orthopedic Traumatology: An Evidence-Based Approach. Springer, NY, USA.

5 Quality statement 5: Subtrochanteric fracture, Hip fracture in adults, Quality standards, NICE.

6 Kubiak EN, Bong M, Park SS, Kummer F, Egol K, Koval KJ. Intramedullary fixation of unstable intertrochanteric hip fractures: one or two lag screws. J. Orthop. Trauma 18(1), 12-17 (2004).

7 Santoni BG, Nayak AN, Cooper SA et al. Comparison of femoral head rotation and varus collapse between a single lag screw and integrated dual screw intertrochanteric hip fracture fixation device using a cadaveric hemi-pelvis biomechanical model. J. Orthop. Trauma 30(4), 164-169 (2016).

8 Huang Y, Zhang C, Luo Y. A comparative biomechanical study of proximal femoral nail (InterTAN) and proximal femoral nail antirotation for intertrochanteric fractures. Int. Orthop. 37(12), 2013).

9 Nherera L, Trueman P, Horner A, Watson T, Johnstone AJ. Comparison of a twin interlocking derotation and compression screw cephalomedullary nail (InterTAN) with a single screw derotation cephalomedullary nail (proximal femoral nail antirotation): a systematic review and meta-analysis for intertrochanteric fractures. J. Orthop. Surg. Res. 13(1), 2018).

-. Significant paper within this area of research.

10 Study Quality Assessment Tools, NHLBI, NIH, (n.d.). www.nhlbi.nih.gov/health-topics/study-quality-assessment-tools

11 Harris WH. Traumatic arthritis of the hip after dislocation and acetabular fractures: treatment by mold arthroplasty. An end-result study using a new method of result evaluation. J. Bone Joint Surg. Am. 51(4), (1969).

12 Zehir S, Şahin E, Zehir R. Comparison of clinical outcomes with three different intramedullary nailing devices in the treatment of unstable trochanteric fractures. Ulus. Travma ve Acil Cerrahi Derg. 21(6), (2015).

13 Yu W, Zhang X, Zhu X, Hu J, Liu Y. A retrospective analysis of the InterTAN nail and proximal femoral nail anti-rotation-Asia in the treatment of unstable intertrochanteric femur fractures in the elderly. J. Orthop. Surg. Res. (2016).

14 Duramaz A, Ilter MH. The impact of proximal femoral nail type on clinical and radiological outcomes in the treatment of intertrochanteric femur fractures: a comparative study. Eur. J. Orthop. Surg. Traumatol. (2019).

15 Seyhan M, Turkmen I, Unay K, Ozkut AT. Do PFNA devices and InterTAN nails both have the same effects in the treatment of trochanteric fractures? A prospective clinical study. J. Orthop. Sci. 20(6), (2015).

16 Wu D, Ren G, Peng C, Zheng X, Mao F, Zhang Y. InterTAN nail versus Gamma3 nail for intramedullary nailing of unstable trochanteric fractures. Diagn. Pathol. (2014).

17 Hopp S, Wirbel R, Ojodu I, Pizanis A, Pohlemann T, Fleischer J. Does the implant make the difference? Prospective comparison of two different proximal femur nails. Acta Orthop. Belg. (2016).

$18 \mathrm{Su} \mathrm{H}$, Sun K, Wang X. A randomized prospective comparison of InterTAN and Gamma3 for treating unstable intertrochanteric fractures. Int. J. Clin. Exp. Med. (2016).

-• Randomized controlled trial (RCT) - most rigorous interventional study comparing InterTAN (IT) and Gamma3.

19 Zhang $\mathrm{H}$, Zeng X, Zhang $\mathrm{N}$ et al. InterTAN nail versus proximal femoral nail antirotation-Asia for intertrochanteric femur fractures in elderly patients with primary osteoporosis. J. Int. Med. Res. (2017).

20 Zhang $\mathrm{C}$, Xu B, Liang G et al. Optimizing stability in AO/OTA 31-A2 intertrochanteric fracture fixation in older patients with osteoporosis. J. Int. Med. Res. (2018).

21 Zhang H, Zhu X, Pei G et al. A retrospective analysis of the InterTAN nail and proximal femoral nail anti-rotation in the treatment of intertrochanteric fractures in elderly patients with osteoporosis: a minimum follow-up of 3 years. J. Orthop. Surg. Res. (2017).

22 Makki D, Matar HE, Jacob N, Lipscombe S, Gudena R. Comparison of the reconstruction trochanteric antigrade nail (TAN) with the proximal femoral nail antirotation (PFNA) in the management of reverse oblique intertrochanteric hip fractures. Injury 46(12), (2015).

23 Imerci A, Aydogan NH, Tosun K. A comparison of the InterTAN nail and proximal femoral fail antirotation in the treatment of reverse intertrochanteric femoral fractures. Acta Orthop. Belg. (2018). 
24 Berger-Groch J, Rupprecht M, Schoepper S, Schroeder M, Rueger JM, Hoffmann M. Five-year outcome analysis of intertrochanteric femur fractures: a prospective randomized trial comparing a 2-screw and a single-screw cephalomedullary nail. J. Orthop. Trauma. 30(9), 2016).

- $\quad$ RCT - most rigorous interventional study comparing IT and Gamma3.

25 Serrano R, Blair JA, Watson DT et al. Cephalomedullary nail fixation of intertrochanteric femur fractures: are two proximal screws better than one? J. Orthop. Trauma. (2017).

- Large study with over 450 patients comparing IT and Gamma3.

26 Takigami I, Matsumoto K, Ohara A et al. Treatment of trochanteric fractures with the PFNA (proximal femoral nail antirotation) nail system report of early results. Bull. NYU Hosp. Jt. Dis. (2008).

27 Gavaskar AS, Tummala NC, Krishnamurthy M. Operative management of Hoffa fractures - a prospective review of 18 patients. Injury (2011).

28 Nikoloski AN, Osbrough AL, Yates PJ. Should the tip-apex distance (TAD) rule be modified for the proximal femoral nail antirotation (PFNA)? A retrospective study. J. Orthop. Surg. Res. (2013).

29 Lenz M, Schwinn J, Hofmann-Fliri L et al. Influence of reduced tip-apex distance on helical blade fixation-a biomechanical study. J. Orthop. Res. (2019).

30 Ma JX, Kuang MJ, Fan ZR et al. Comparison of clinical outcomes with InterTAN vs Gamma nail or PFNA in the treatment of intertrochanteric fractures: a meta-analysis. Sci. Rep. (2017).

-. Significant paper within this area of research. 